\title{
A highly sensitive modified nested PCR to enhance case detection in leishmaniasis
}

\author{
Bhagya Deepachandi ${ }^{1}$, Sudath Weerasinghe ${ }^{1}$, Preethi Soysa ${ }^{2}$, Nadira Karunaweera ${ }^{1}$ and Yamuna Siriwardana ${ }^{{ }^{*}}$ (D)
}

\begin{abstract}
Background: Human leishmaniasis is one of the major parasitic diseases with worldwide distribution. Sri Lanka is a recently established focus of leishmaniasis caused by a variant Leishmania donovani. Early case detection and management is a main approach identified for L. donovani control in the regional leishmaniasis elimination drive. Usefulness of light microscopy and in-vitro culture are limited in chronic, atypical or treated lesions though timely and accurate detection of all light microscopy/in-vitro culture negative cases of all forms of leishmaniasis is necessary for treatment. Timely treatment is important to minimize risk for death in visceral disease and undesired sequelae of long standing infection and illness on both patients and community. We described a 100\% sensitive, Leishmania spp. specific modified version of a nested PCR (Mo-STNPCR) that also minimizes carry over and cross contaminations while facilitate investigation of light microscopy and in-vitro culture negative clinically suggestive cases of leishmaniasis.

Methods: Leishmania DNA was amplified using previously published P221: 5'-GGTTCCTTCCTGATTACG-3' and P332: 5'-GGCCGGTAAAGGCCGAATAG-3'outer primers followed by a nested reaction using P223: 5'-TCCC ATCGCAACCTCGGTT-3' and P333: 5'-AAGCGGGCGCGGTGCTG-3' inner primers that by passes the requirement of tube handling between the two steps of the conventional nested PCR. Leishmania DNA was detected in a range of infected tissue material. Infected material from patients with cutaneous leishmaniasis $(n=30)$, visceral leishmaniasis $(n=10)$ and from a control group including patients with non-leishmanial skin diseases $(n=10)$, other systemic diseases $(n=10)$ and healthy individuals $(n=10)$ were examined with Mo-STNPCR. Results were further compared with those of light microscopy and in-vitro culture.

Results: Mo-STNPCR method was 100\% sensitive and 100\% specific for diagnosis of leishmaniasis. Light microscopy and in-vitro culture were positive in $75.0 \%(n=30 / 40)$ and $72.5 \%(n=29 / 40)$ samples respectively where combined results of them gave $87.5 \%(n=35 / 40)$ sensitivity. Mo-STNPCR did not cross react with control samples.

Furthermore, Mo-STNPCR reduces the risk of cross-contaminations and carry over contaminations since the full reaction is carried out without opening the tubes. Per patient cost was calculated as 22 USD while the same was 3 and 6 USD for light microscopy and in-vitro culture respectively.
\end{abstract}

Conclusion: Mo-STNPCR method is a useful tool in detecting leishmaniasis in minority of cases that go undetected by first line investigations.

Keywords: Leishmaniasis, Diagnosis, PCR, L. donovani

\footnotetext{
*Correspondence: yamuna@parasit.cmb.ac.lk

${ }^{1}$ Deparment of Parasitology, Faculty of Medicine, University of Colombo,

Colombo, Sri Lanka

Full list of author information is available at the end of the article
}

(c) The Author(s). 2019 Open Access This article is distributed under the terms of the Creative Commons Attribution 4.0 International License (http://creativecommons.org/licenses/by/4.0/), which permits unrestricted use, distribution, and reproduction in any medium, provided you give appropriate credit to the original author(s) and the source, provide a link to the Creative Commons license, and indicate if changes were made. The Creative Commons Public Domain Dedication waiver (http://creativecommons.org/publicdomain/zero/1.0/) applies to the data made available in this article, unless otherwise stated. 


\section{Background}

All clinical forms of leishmaniasis are associated with high morbidity and also with mortality in the case of VL and MCL [1]. Human leishmaniasis continue to remain a major health issue in many countries despite many efforts in disease control [1]. There is a regional leishmaniasis elimination drive for $L$. donovani infections in the Indian subcontinent (ISC) that aims at achieving its targets by year 2020 [2].

Sri Lanka is a recent focus of human leishmaniasis in ISC with $L$. donovani being the causative agent [3-5]. So far, in a clear majority of reported local cases the disease is apparent in the form of CL [3, 6-8]. Early disease confirmation and management is considered very important in disease control of $L$. donovani. Recent emergence of VL and MCL [9-11], poor treatment response [12], micro changes within CL profile [13], widening case distribution [8], atypical manifestations $[12,13]$, regionally varied risk factors [14-16] and questionnable potential for visceralization [17] further necessitates urgent action in this locality. Detection of all infections and all clinically apparent cases are important. VL essentially requires pre-treatment laboratory confirmation of all cases.

Success rate of first line investigation, light microscopy (LM) depend on parasite load and technical handling though it is the cheapest, least complex, quick and field friendly. Low parasite counts in chronic and partially treated infections usually lead to false-negative results when traditional diagnostic assays are used. Therefore, more sensitive tools are required to detect those clinically suspected cases that turn negative in LM. In-vitro culturing (IVC) of parasites is complex, expensive and time consuming while reporting can take time depending on parasite growth in culture media. All Leishmania inoculations do not end up in successful parasite growth in artificial media. Molecular detection of Leishmania using PCR is the most sensitive method to date. However, molecular techniques are highly expensive, require sophisticated laboratory facilities and require technical expertise limit its usage for performance in resource poor endemic field areas [18]. However, availability of a highly sensitive PCR assay at a central laboratory would be extremely useful to establish an immediate diagnosis in microscopy negative minority that demands a quick diagnosis. Most researchers have shown PCR as a sensitive and specific tool for diagnosis of leishmaniasis and shown excellent correlations between PCR results and other diagnostic methods such as parasitological and serological tests. Conventional single-step PCR (CPCR), quantitative real-time PCR (qPCR), nested PCR (NPCR) and PCR-restriction fragment length polymorphism (PCR-RFLP) are widely used to detect different genetic sequences of Leishmania such as kinetoplastid DNA
(kDNA), internal transcribed spacer (ITS) region, and small subunit ribosomal RNA (ssurRNA) [19-23].

PCR protocols and loop-mediated isothermal amplification (LAMP) have been tested locally [18, 24]. The LAMP is a relatively less complex method that is costeffective and require low performance time [18]. But the low sensitivity rate of LAMP limits its use as a diagnostic tool. Furthermore, in the local settings Leishmania genus-specific kDNA and ITS1 PCR assays have demonstrated $92 \%$ sensitivity, while the sensitivity level of $L$. donovani species-specific kDNA assay is only 71\% [24].

NPCR is a modification of CPCR and employs two sets of primers and two successive PCR reactions. Although the conventional nested PCR is one of the most sensitive PCR techniques, the possible cross-contaminations and carry over contaminations are the major difficulties associated [25]. They may occur during opening of reaction tubes during preparation for the second step amplification by transferring amplicons already produced during the first amplification step, subsequently result in false positives and therefore reduce the accuracy of the test. STNPCR described here involves both first and second PCR reactions of nested PCR, but both placed in one tube by immobilizing inner primers on inner side of cap of PCR tube and dissolving before the second round of PCR [25]. Therefore it reduces the possibility of crosscontaminations during procedure. The STNPCR methods have been proven useful in detection of a range of conditions [25-29]. STNPCR method has been proven useful in detection of low amounts of parasite DNA as well [25].

Present study evaluated the performance of a further modified nested PCR (Mo-STNPCR) method to achieve better sensitivity, specificity and to avoid possible crosscontamination and carry over contaminations associated with conventional NPCRs.

\section{Methods \\ Primer selection}

Two pairs of primers, outer (P221: 5'-GGTTCCTT TCCTGATTTACG-3' and P332: 5'-GGCCGGTAAAG GCCGAATAG-3') and inner (P223: 5' -TCCCATCGCA ACCTCGGTT-3' and P333: 5'-AAGCGGGCGCGGTG CTG-3') primers were employed (Fig. 1a) [18]. P221 and P332 primers were designed to amplify kDNA of genus Leishmania. Although P221 and P332 primers may amplify the other kinetoplastida such as Leptomonas and Crithidia, inner primers (P223 and P333) were designed as specific for Leishmania genus [30]. As published by Cruz et al, the sequence analysis of inner primers with BLAST (basic local alignment search tool) at NCBI (National center for biotechnology information) confirmed the $100 \%$ specificity of these primers only to Leishmania and therefore no amplification occurs 
a

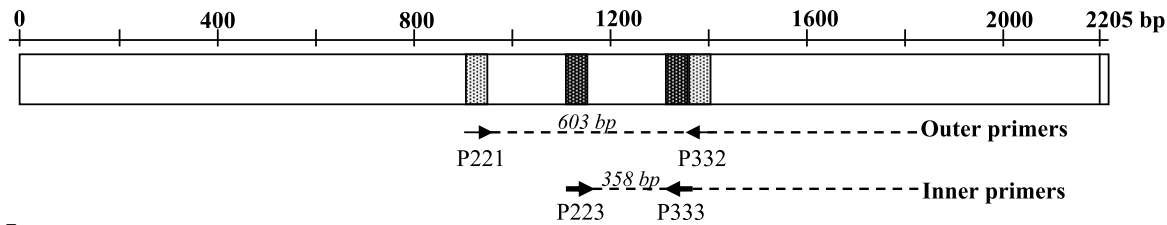

b

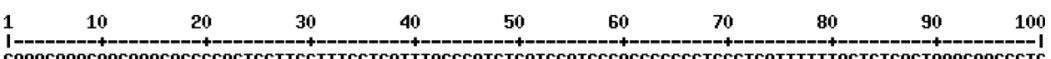

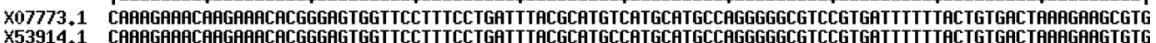
Y00055.1 CAAAGAAFCAAGAAACACGGGGG TGGTTCCTTCC TGATITACGCATGTCATGCATGCCAGGGGGCGTCCGTGATIITITACTGTGACTAAAGAAGTGTG

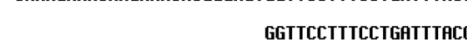

Outer primer
P223

Consensus

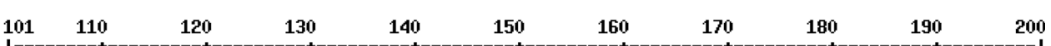

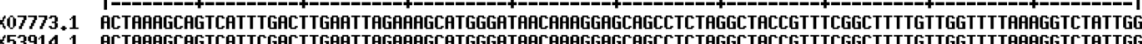

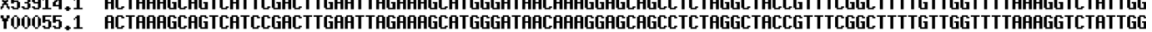

P221
P333
Consensus

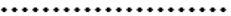

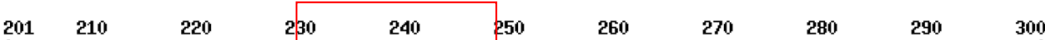

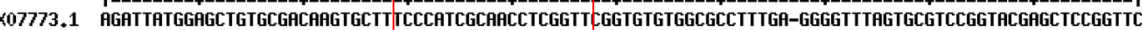
X53914 1 1

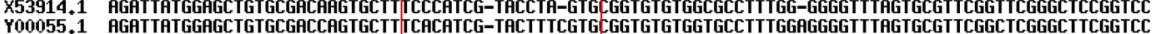

$\mathrm{P} 223$

Consensus

Inner prime TCCCATCGCAACCTCGGTT

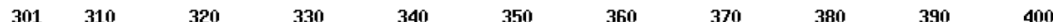

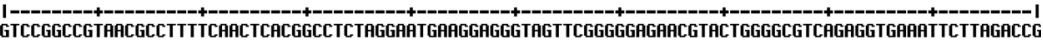
X07773.1 Yo0055.1 GTCCGGGCGTAACGCCTCTTCAACTCACGGCCTCTAGGAATGAAGGGGGGTAGTTCGGGGGGGACGTACTGGGGCGTCAGAGGTGAAATTCTTAGACCG

P221

P333

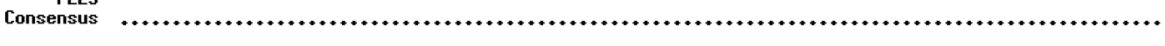

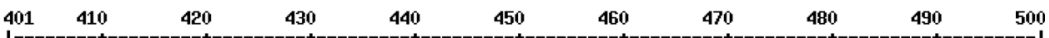

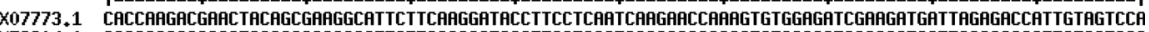
$\times 53914.1$ CACCAAGCGACGCACGCG

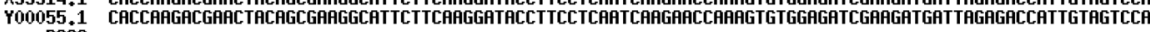

P332

P221

P233
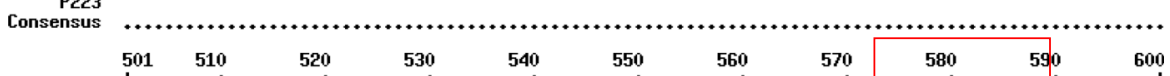

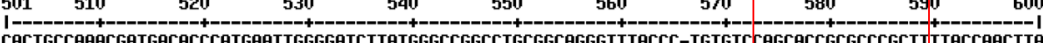

X07773.1 CACTGCCAAACGATGACACCCATGAATTGGGGATCTIATGGGCCGGCCTGCGGCAGGGTTTACCC-TGTGTCCAGCACCGCGCCCGCTTIITACCAACTTA

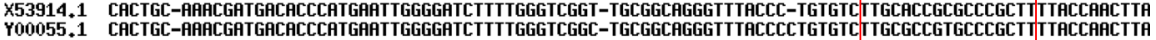

Y00055.1
P332

P332
P221
P333

Consensus

\begin{tabular}{l|l} 
Inner primer &
\end{tabular}

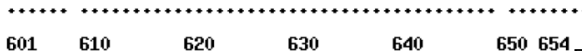

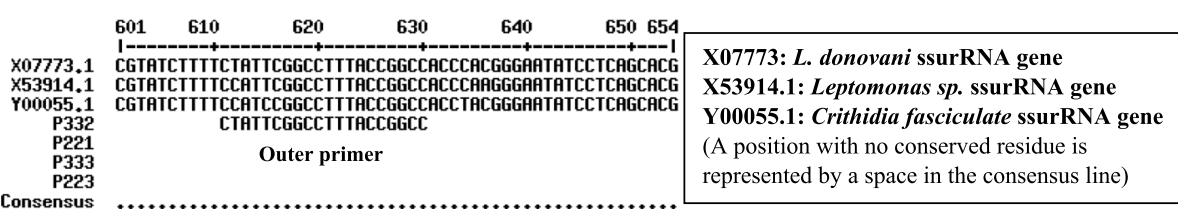

Fig. 1 a: Annealing sites of P221-P332 and P223-P333 in L. donovani gene for ssurRNA (GenBank: X07773.1) [31]. b: Sequence difference of selected kinetoplastid organisms showing specificity of inner and outer primers [31]

with other organisms (Fig. 1b) [30]. But as shown in Fig. $1 \mathrm{~b}$, the region amplified by the inner primers are present in other kinetoplastids (eg: Leptomonas and Crithidia) with some changes in nucleotide sequences between those organisms.

\section{Sample size determination}

The sample size required for the study was calculated according to following standard formulas, $[\mathrm{TP}+\mathrm{FN}=$ $\mathrm{Z}^{2} \times(\mathrm{SN}(1-\mathrm{SN})) / \mathrm{W}^{2}$ and $\mathrm{n}=(\mathrm{TP}+\mathrm{FN}) / \mathrm{P}$ where $\mathrm{TP}$ : true positive, $\mathrm{FN}$ : false negative, $\mathrm{SN}$ : lowest acceptable 
sensitivity of diagnostic test used; According to previously published data, STNPCR method was 100\% sensitive for diagnosis ([28]. Therefore $\mathrm{SN}$ was taken as 98.0\% for sample calculation, Z: normal distribution value at particular confidence interval (i.e. for $95 \%, Z=$ 1.96), P: leishmaniasis prevalence within the suspected group of patients (the clinically suspected group of CL patients referred to Department of Parasitology, Faculty of Medicine, University of Colombo); According to a recent study, the prevalence of suspected group of patients referred to the department was found as $86.4 \%$ [8]. Therefore $P$ value was taken as about $80.0 \%$ for sample calculation, W: represents accuracy; A $5.0 \%$ of sensitivity of confidence interval is the standard value determined according to sample size calculation methods and n: sample size] [32]. $\mathrm{TP}+\mathrm{FN}$ and $\mathrm{n}$ were calculated as 30.12 and 37.6 respectively. When $n=37.6$ (approximately $n=38$ ), total samples to be analyzed from a suspected population of leishmaniasis with $80.0 \%$ disease prevalence and with $98.0 \%$ expected sensitivity of the Mo-STNPCR method was about $n=70$. A total of 70 (40 patients suspected for CL and 30 patients suspected for $\mathrm{VL}$ ) patients were included in the study.

\section{Sample collection}

Samples were collected from the patients referred to Department of Parasitology, Faculty of Medicine, University of Colombo after informed written consent. Laboratory confirmation of samples were done by LM, IVC [33] and/or CPCR [34]. The selected $n=30 \mathrm{CL}$ and $n=10$ VL patients confirmed for leishmaniasis were used for evaluating Mo-STNPCR method. The control group included NCL ( $n=5$ cutaneous TB and $n=5$ leprosy), NVL $(n=10)$ and HC $(n=10)$. From the CL and NCL patients, lesion material (lesion aspirates or slit-skin scrapings, $n=25)$ and skin biopsies $(n=15)$ were collected. Bone marrow aspirates were collected from all VL and NVL patients. Peripheral blood $(n=5)$ or skin materials/skin cells collected by impression with a glass slide in non-invasive manner $(n=5)$ were collected from healthy individuals to normalize the effect of type of tissue.

\section{DNA preparation}

DNA extractions from the samples were done using Qiagen mini DNA extraction kit in accordance with manufacturer's guidelines. A minimum sample amount of $200 \mu \mathrm{l}$ was aliquoted from body fluids such as blood, bone marrow, lesion aspirates or slit-skin scrapings. Twenty (20) $\mu \mathrm{l}$ of proteinase $\mathrm{K}$ and $200 \mu \mathrm{l}$ of lysis buffer were added to each sample. Tubes were incubated in a water bath at $56^{\circ} \mathrm{C}$ for $10 \mathrm{~min}$ following vortexing for $15 \mathrm{~s}$. Body tissues (skin biopsies, about $2 \mathrm{~mm}$ sized) were subjected to additional tissue disruption (cut into small pieces) with the buffer provided by manufacturer. The lysis of body tissues/skin biopsies were cut into small pieces for facilitating complete lysis of the tissue with the buffer and proteinase $\mathrm{K}$ provided (Also if require, additional mechanical disruption using a homogenizer can reduce the lysis time of the sample. Complete lysis of cells is required to yield a high DNA yield since body tissues have an abundance of contractile proteins, connective tissue and collagen). After adding $20 \mu \mathrm{l}$ of proteinase $\mathrm{K}$, the samples and reagents were mixed by vortexing. Then they were incubated at $56^{\circ} \mathrm{C}$ for $1-3 \mathrm{~h}$ until completely lysed. Occasional vortexing of the samples was done during the incubation period. An additional incubation was carried out for all body tissue samples at $70^{\circ} \mathrm{C}$ for $10 \mathrm{~min}$ after mixing with $200 \mu \mathrm{l}$ of lysis buffer.

All the lysed samples were mixed well by vortexing with $200 \mu \mathrm{l}$ of absolute ethanol and transferred to DNA extraction columns. After centrifuging the columns at $8000 \mathrm{rpm}$ for $1 \mathrm{~min}$, two washing steps were carried out using $500 \mu \mathrm{l}$ of each wash buffer provided by the manufacturer by centrifuging at $8000 \mathrm{rpm}$ for $1 \mathrm{~min}$ and 12 , $000 \mathrm{rpm}$ for $1 \mathrm{~min}$ respectively. Finally, the DNA samples were eluted from binding columns by adding $200 \mu \mathrm{l}$ of elution buffer followed by $5 \mathrm{~min}$ incubation at room temperature and centrifugation at $8000 \mathrm{rpm}$ for $1 \mathrm{~min}$. The extracted DNA samples were stored at $4{ }^{\circ} \mathrm{C}$ in a refrigerator until further use. Long-term storage was done at $-20^{\circ} \mathrm{C}$.

\section{Negative and positive controls for Mo-STNPCR}

Total genomic DNA extracted from a cell pellet of $L$. donovani (local reference strain of Leishmania) promastigote mass culture was used as the reference positive control. For the quality assurance of the new test, negative controls were run parallel to the positive control in each round of PCR. Few negative controls were used including PCR reactions containing only inner primers, only outer primers, both primers without template DNA and both primers with DNA coming from a negative extraction. These different negative controls further enhanced the quality of the test by excluding any nonspecific amplifications, contaminations of reagents used for DNA extraction and PCR. The lowest detection limit of the Mo-STNPCR was tested using a standard series of a positive control with a known concentration. Ten-fold dilutions were prepared from the positive control which contained $1 \mu \mathrm{g}$ to $1 \mathrm{fg}$ of DNA and they were amplified using Mo-STNPCR (Fig. 2).

\section{Mo-STNPCR method}

A mixture of inner primers including forward (P223: $5^{\prime}$ TCCCATCGCAACCTCGGTT-3') and reverse (P333: 5'-AAGCGGGCGCGGTGCTG-3') primers [18] with 


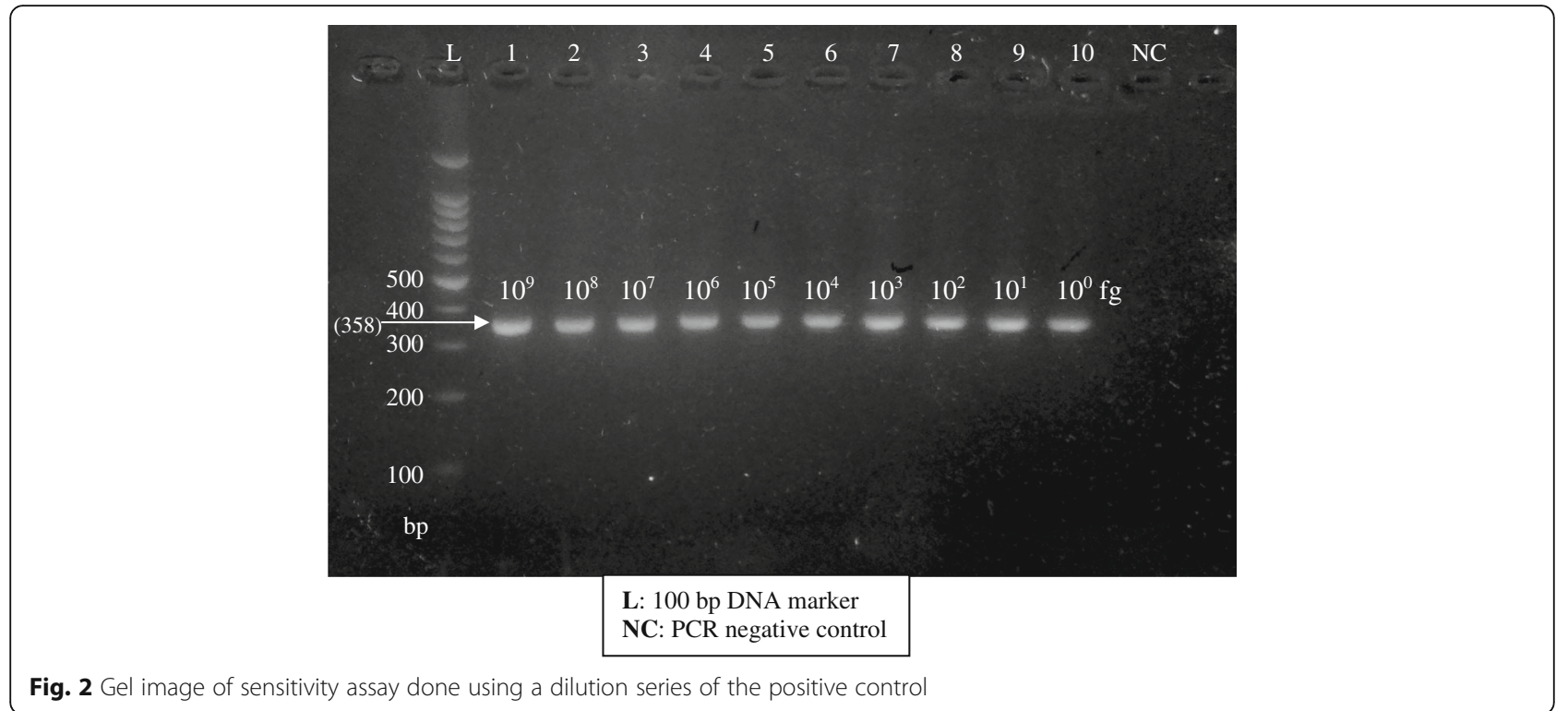

traces of bromophenol blue was prepared by adding 1:1: 1 ratio of forward primer $(10 \mu \mathrm{M})$, reverse primer $(10 \mu \mathrm{M})$ and bromophenol blue [25]. A total of $3 \mu \mathrm{l}$ of inner primers of the nested PCR were immobilized on to the inner side of cap of PCR tubes prior to adding PCR mixture to each tube. The immobilization was done by allowing the primers-bromophenol blue mixture to air dry at room temperature $\left(24^{\circ} \mathrm{C}\right)$ for about $2-3 \mathrm{~h}$ by keeping the cap of tubes open at a horizontal position on a PCR tube rack. These primer immobilized PCR tubes were stored at $-20^{\circ} \mathrm{C}$ until further use.

PCR reaction mixture was prepared by adding outer primers of the nested PCR (forward primer $(10 \mu \mathrm{M}), \mathrm{P} 221$ : 5'-GGTTCCTTTCCTGATTTACG-3' and reverse primer $(10 \mu \mathrm{M})$, P332: 5 '-GGCCGGTAAAGGCCGAATAG-3') $[18,34]$ at a ratio of 10:1 between inner primers: outer primers. PCR reaction was set up using the optimized volumes of PCR Taq master mix (abm/ Applied Biological Materials, Canada) and other reagents as shown in Table 1. The PCR programme was run for 15 cycles in first step and 35 cycles in second step (Table 2).

\section{Gel electrophoresis}

Ten microliters of PCR products against the $100 \mathrm{bp}$ DNA ladder were analyzed on $2.0 \%$ agarose gels consisted with

Table 1 Components of PCR master mix

\begin{tabular}{ll}
\hline PCR water & $19.8 \mu \mathrm{l}$ \\
\hline 2XPCR Taq master mix (abm, G013) & $25.0 \mu \mathrm{l}$ \\
Forward, outer primer (P221) & $0.1 \mu \mathrm{l}$ \\
Reverse, outer primer (P332) & $0.1 \mu \mathrm{l}$ \\
Template DNA & $5.0 \mu \mathrm{l}$ \\
Total & $50.0 \mu \mathrm{l}$ \\
\hline
\end{tabular}

ethidium bromide. DNA bands were visualized with an ultraviolet light transilluminator. Positive samples yielded a PCR product of $358 \mathrm{bp}$.

\section{Other techniques for comparison}

As described above, lesion aspirates, slit-skin scrapings or skin biopsies collected from CL and NCL patients, bone marrow collected from VL and NVL patients and peripheral blood or skin materials collected from $\mathrm{HC}$ were analyzed and compared with LM, IVC and CPCR. All CL $(n=30)$, VL $(n=10)$, NCL $(n=10)$, NVL $(n=10)$ and $\mathrm{HC}(n=10)$ samples were analyzed using LM. Also IVC was carried out for all CL, VL and NVL samples while all VL, NVL, HC and some CL $(n=10 / 30)$ samples were further confirmed with CPCR. In LM, Giemsastained smears were microscopically examined with 1000× magnification [33]. Minimum of 100 fields were observed before marked as negative. The micro-capillary culture method was used for IVC with complete M199 media (Gibco) [33]. IVC were observed until completion of two weeks from initial inoculation before marked as negative. CPCR was done using previously established standard protocols using P221 and P332 primers [34].

\section{Validation and data analysis}

A sample was taken as Leishmania positive if it was positive by any one of the control tests performed viz. LM, IVC or CPCR. Reproducibility or repeatability of the assay was determined over one year period by performing a known positive and known negative samples in each round of Mo-STNPCR. Sensitivity, specificity, NPV and PPV were calculated using the standard $2 \times 2$ tables. Accuracy of the test was also determined using standard calculation methods (Accuracy $=$ true positives 
Table 2 PCR programme for Mo-STNPCR

\begin{tabular}{|c|c|c|c|}
\hline \multicolumn{4}{|c|}{ First round of amplification (about 45 minutes) } \\
\hline Initial denaturation & $95^{0} \mathrm{C}$ & $3 \mathrm{~min}$ & \multirow{5}{*}{15 cycles } \\
\hline Denaturation & $94^{\circ} \mathrm{C}$ & $30 \mathrm{sec}$ & \\
\hline Annealing & $53^{\circ} \mathrm{C}$ & $30 \mathrm{sec}\}$ & \\
\hline Extension & $72^{0} \mathrm{C}$ & $30 \mathrm{sec} J$ & \\
\hline Final incubation & $95^{0} \mathrm{C}$ & $1 \mathrm{~min}$ & \\
\hline \multicolumn{4}{|c|}{$\begin{array}{l}\text { After approximately } 1 \text { minute of incubation at } 95^{\circ} \mathrm{C} \text {, the tubes were inverted several times to } \\
\text { dissolve the inner primers. Then the tubes were spun and returned to the thermocycler for the } \\
\qquad \text { second round of amplification. }\end{array}$} \\
\hline \multicolumn{4}{|c|}{ Second round of amplification (about 1.5 hour) } \\
\hline Initial denaturation & $95^{0} \mathrm{C}$ & $3 \mathrm{~min}$ & \multirow{6}{*}{35 cycles } \\
\hline Denaturation & $94^{0} \mathrm{C}$ & $30 \mathrm{sec}$ & \\
\hline Annealing & $65^{\circ} \mathrm{C}$ & $30 \mathrm{sec}$ & \\
\hline Extension & $72^{0} \mathrm{C}$ & $30 \mathrm{sec} J$ & \\
\hline Final extension & $72^{\circ} \mathrm{C}$ & $5 \min$ & \\
\hline & & n $4^{0} \mathrm{C}$ & \\
\hline
\end{tabular}

and true negatives/total number of samples). To further validate the Mo-STNPCR, the assay results were compared with classical parasitological diagnostic methods used for diagnosis of leishmaniasis, LM and IVC [33] and CPCR [34]. It aided in the determination of usefulness of Mo-STNPCR as a diagnostic tool.

\section{Cost analysis for Mo-STNPCR method}

Cost analysis per patient was carried out according to approved guidelines of basic cost accounting for clinical services [35]. Briefly, expenses for DNA extraction and Mo-STNPCR, laboratory consumables, chemicals and reagents were estimated according to their current cost

Table 3 Details of items used for evaluating the per patient cost of Mo-STNPCR

\begin{tabular}{ll}
\hline Major steps of Mo-STNPCR & $\begin{array}{l}\text { Considered items for per patient cost } \\
\text { analysis of Mo-STNPCR }\end{array}$ \\
\hline Sample collection & $\begin{array}{l}\text { Sample collection tubes and other } \\
\text { materials required for sample collection } \\
\text { DNA extraction kits for sample, } \\
\text { DNA extraction }\end{array}$ \\
PCR procedure control and negative control \\
mix (abm, G013), outer primers \\
(P221 and P332) and inner primer \\
(P223 and P333), bromophenol blue \\
Gel running buffer, ethidium bromide, \\
agarose \\
Micro-centrifuge tubes, PCR tubes, \\
pipette tips, phosphate buffered saline, \\
issuing laboratory reports
\end{tabular}

in USD (Table 3). The expenses for laboratory personnel and equipment were not considered for the analysis.

\section{Results}

The lowest detection limit of DNA in the Mo-STNPCR method was $1 \mathrm{fg}$, which was the lowest tested concentrations (Fig. 2).

The analysis and comparison of other diagnostic methods (LM, IVC and CPCR) of leishmaniasis confirmed the diagnosis of leishmaniasis and verified the positive and negative results obtained for Mo-STNPCR (Table 4). The positivity rates of other diagnostic methods tested were $75 \%(n=30 / 40)$ and $72.5 \%(n=29 /$ 40) for LM (Table 5) and IVC respectively. Also the combined LM and IVC gave $87.5 \%(n=35 / 40)$ positivity (Table 6). As compared to LM and IVC, Mo-STNPCR showed $100 \%(n=40 / 40)$ positivity for the study group of leishmaniasis. Also all negative control samples including patients with other non CL skin diseases (NCL), patients with other non VL systemic diseases (NVL) and healthy individuals ( $\mathrm{HC}$ ) gave negative results in Mo-STNPCR.

The accuracy of Mo-STNPCR method was calculated as $100.0 \%$ where $n=40$ true positives, $n=30$ true negatives and $n=70$ of total samples for CL, VL and control group together (Table 4). The Mo-STNPCR method was $100.0 \%$ repeatable. There was no difference between the results of Mo-STNPCR and combined LM, IVC and CPCR results of analyzed samples. But low positivity of other diagnostic tests as mentioned above confirmed the high sensitivity and accuracy of Mo-STNPCR method 
Table 4 Diagnostic $2 \times 2$ table. Sensitivity, specificity, negative predictive value (NPV) and positive predictive value (PPV) of the MoSTNPCR method were determined by comparing to conventional parasitological methods, LM, IVC and CPCR

\begin{tabular}{|c|c|c|c|c|c|}
\hline & & \multicolumn{2}{|c|}{ Combined laboratory results (LM, IVC and CPCR) } & \multirow[b]{2}{*}{ Total count } & \\
\hline & & Positive & Negative & & \\
\hline \multirow{4}{*}{$\begin{array}{l}\text { Mo-STNPCR } \\
\text { method }\end{array}$} & Positive & 40 & 0 & 40 & $P P V=(40 / 40) \times 100 \%=100.0 \%$ \\
\hline & Negative & 0 & 30 & 30 & $N P V=(30 / 30) \times 100 \%=100.0 \%$ \\
\hline & Total Count & 40 & 30 & 70 & \\
\hline & & Sensitivity $=(40 / 40) \times 100 \%=100.0 \%$ & Specificity $=(30 / 30) \times 100 \%=100.0 \%$ & & \\
\hline
\end{tabular}

compared to those individual diagnostic methods. Per patient cost was calculated as 22 USD while the same was 3 and 6 USD for light microscopy and in-vitro culture respectively.

\section{Discussion}

This study produced a fully sensitive diagnostic tool to detect leishmaniasis while enabling the exclusion of Crithidia spp. and Leptomonas spp. which are nonleishmanial pathogens that can complicate detection of Leishmania spp. in IVCs as well as in some widely used CPCR methods [34]. qPCR method is another PCR technique with high sensitivity and specificity. In qPCR, an intercalating dye or fluorescence probe are used for quantifying number of amplified DNA molecules using the strength of signal produced by them. Although qPCR is with high sensitivity and specificity and avoids the requirement for post amplification analysis of PCR, the disadvantages of qPCR which are the high cost, complexity and technically demanding nature limit its usage ([21]). qPCR is currently not available for diagnosis in all Leishmania diagnostic laboratories within the country. Mo-STNPCR can be carried out in conventional PCR machine and therefore it is highly applicable than qPCR for diagnosis of Leishmania.

CPCR amplifies a region of about $603 \mathrm{bp}$ in ssurRNA of Leishmania genome $[34,36]$. CPCR was approximately 95\% ( $n=38 / 40)$ sensitive for detection of leishmaniasis according to the past records (for a different sample group studied within the centre). Albeit it can amplify Leishmania species, Leptomonas and Crithidia species [30]. This is a major disadvantage of the CPCR since Leptomonas and Crithidia can co-exist with Leishmania and leads to misdiagnosis even if they are non-pathogenic to humans $[37,38]$. In the absence of an indicative skin lesion and in the presence of nonspecific clinical features in VL, skin tissue or bone marrow examination needs careful exclusion of these pathogens. This problem was overcome by designing a new primer pair, P223 and P333 which amplified a region between the amplicon of P221 and P332 as shown in Fig. 1 and thus they were used as inner primers of the nested PCR method described [30]. The region amplified by P223 and P333 is specific only to Leishmania genus and therefore it excludes the amplification of Leptomonas and Crithidia species according to the BLAST search carried out on published GenBank data. Therefore the NPCR done using P223 and P333 inner primers are 100\% specific for detection of Leishmania parasites [18, 30].

STNPCR technique was also called as "drop-in/dropout" nested PCR which consisted inner and outer primers with vastly different annealing temperatures thereby initially allowed only the outer primers to amplify and subsequently the inner primers to amplify the nested fragment [39-41]. Therefore this method restricted the selection of primers since it required significantly different annealing temperatures [42]. Also the different research groups tried to physically separate the first and second round amplifications by using different procedures with different materials such as a thin layer of mineral oil, agarose resin and trehalose matrix [43-45]. But these methods are cumbersome, required the use of specially designed reaction tubes and presence of extraneous materials might interfere with the PCR [42]. The inner primers showed activity (with the positive PCR bands) only where tubes were inverted and dissolve the inner primers fixed inside the lid. The

Table 5 Diagnostic $2 \times 2$ table. Sensitivity, specificity, NPV and PPV of the Mo-STNPCR method were determined by comparing to LM

\begin{tabular}{llllll}
\hline & & LM & & \\
\cline { 3 - 5 } & & Positive & Negative & Total count & \\
\hline Mo-STNPCR & Positive & 30 & 10 & 40 & $P P V=(30 / 40) \times 100 \%=75.0 \%$ \\
method & Negative & 0 & 30 & 30 & $N P V=(30 / 30) \times 100 \%=100.0 \%$ \\
& Total Count & 30 & 40 & 70 & \\
& & Sensitivity $=(30 / 30) \times 100 \%=100.0 \%$ & Specificity $=(30 / 40) \times 100 \%=75.0 \%$ & & \\
\hline
\end{tabular}


Table 6 Diagnostic $2 \times 2$ table. Sensitivity, specificity, NPV and PPV of the Mo-STNPCR method were determined by comparing to combined LM and IVC results

\begin{tabular}{|c|c|c|c|c|c|}
\hline & & \multicolumn{2}{|c|}{ Combined laboratory results (LM and IVC) } & \multirow[b]{2}{*}{ Total count } & \\
\hline & & Positive & Negative & & \\
\hline \multirow{4}{*}{$\begin{array}{l}\text { Mo-STNPCR } \\
\text { method }\end{array}$} & Positive & 35 & 5 & 40 & $P P V=(35 / 40) \times 100 \%=87.5 \%$ \\
\hline & Negative & 0 & 30 & 30 & $N P V=(30 / 30) \times 100 \%=100.0 \%$ \\
\hline & Total Count & 35 & 35 & 70 & \\
\hline & & Sensitivity $=(35 / 35) \times 100 \%=100.0 \%$ & Specificity $=(30 / 35) \times 100 \%=85.7 \%$ & & \\
\hline
\end{tabular}

monitoring of color change of reaction mixture [the mixture was converted to light blue color after dissolving with inner primers (mixed with bromophenol blue)] also re-confirmed the stability of inner primers inside the lid against possible evaporation and condensations.

STNPCR employed in this study has been successfully applied for detection of other pathogenic microorganisms such as Schistosoma mansoni [42, 46], Plasmodium falciparum [47], Yersinia pestis [48], dengue virus serotypes [26], Vibrio cholera O1 [27], Leishmania chagasi [25], Porcine Circovirus type 2 [28] and Mycobacterium tuberculosis [29], causing range of clinical conditions.

Current study used a new combination of previously established inner and outer primers and they were examined using modifications to the technique. The results of Mo-STNPCR showed high sensitivity, specificity (each $100.0 \%)$ and therefore a high accuracy for diagnosis of leishmaniasis. Furthermore, NPCR is likely to have limited use as a diagnostic tool due to carry over and cross-contaminations. Strict adherence to protocol from DNA extraction step onwards would ensure best results in Mo-STNPCR. Also there may be a loss of reactants due to same initial PCR mixture being used for both rounds of PCR in Mo-STNPCR method. However, the selection of a satisfactory primer ratio between inner and outer primers can ensure sufficient reactants until completion of the reaction. It is also important to avoid excessive primer concentrations to prevent creation of $603 \mathrm{bp}$ band in second round of amplification and other non-specific PCR products [45].

\section{Conclusions}

Late presentations, atypical presentations and chronic non-treatment responsive cases in an endemic setting limit the usefulness of clinical detection as well as microscopic or culture detection of leishmaniasis. Furthermore, VL detection requires tools that ideally diagnose $100 \%$ cases due to the essential needs of both death prevention and laboratory confirmation prior to introducing toxic and expensive treatment modalities. LM/IVC does not detect all cases. Even though such scenarios often constitute the minority in an endemic setting, establishing a diagnosis in all cases is necessary. In such a situation level of sensitivity become more important as compared to the cost of investigation, simplicity or the wider availability. The new MoSTNPCR test described here can easily replace the CPCR with better results and may be used as a useful tertiary level assay for detection of all LM and IVC negative leishmaniasis cases in Sri Lanka and other leishmaniasis endemic settings.

\section{Abbreviations}

CL: Cutaneous leishmaniasis; CPCR: Conventional single-step PCR; DNA: Deoxyribonucleic acid; HC: Healthy individuals; ITS: Internal transcribed spacer; IVC: In-vitro culturing; kDNA: Kinetoplastid DNA; LM: Light microscopy; MCL: Muco-cutaneous leishmaniasis; Mo-STNPCR: Modified single tube-nested PCR; NCL: Non CL skin diseases; NPCR: Nested PCR; NPV: Negative predictive value; NVL: Non VL systemic diseases; PCR: Polymerase chain reaction; PKDL: Post-kala-azar dermal leishmaniasis; PPV: Positive predictive value; ssurRNA: Small subunit ribosomal RNA; VL: Visceral leishmaniasis

\section{Acknowledgements}

The authors thank Yasasmi Gange, Sashika Dayananda and Nirosha Pathirana for the technical assistance.

\section{Authors' contributions}

$\mathrm{BD}$ and YS conceptualized and designed the project. BD conducted laboratory experiments, data curation and drafted the manuscript. SW contributed to data acquisition and experiments, PS contributed to technical and academic guidance. NK provided infra structure support. YS provided academic and technical guidance to BD in all steps, funding and revised the manuscript. All the authors read and approved the final manuscript.

\section{Funding}

The research reported here was supported by University of Colombo research grants (AP/3/2/2014/RG/13) and NIH/USA grants (R01Al099602 and U01Al136033). The content is solely the responsibility of the authors and does not necessarily represent the official views of the mentioned funding sources.

\section{Availability of data and materials}

The data supporting the conclusions of this article are included within the article. Additional details are available from the corresponding author on reasonable request.

\section{Ethics approval and consent to participate}

The study received the approval from the Ethics Review Committee, Faculty of Medicine, University of Colombo. Informed written consent was obtained from all the individuals prior to recruitment.

Consent for publication

Not applicable.

Competing interests

The authors declare that they have no competing interests. 


\section{Author details}

Deparment of Parasitology, Faculty of Medicine, University of Colombo, Colombo, Sri Lanka. ${ }^{2}$ Department of Biochemistry and Molecular Biology, Faculty of Medicine, University of Colombo, Colombo, Sri Lanka.

\section{Received: 6 February 2019 Accepted: 11 June 2019 Published online: 15 July 2019}

\section{References}

1. Control of the leishmaniases. Report of a meeting of the WHO expert committee on the control of leishmaniasis, 2010. Contract No: 949. http:// apps.who.int/iris/bitstream/handle/10665/44412/WHO_TRS_949_eng. pdf? sequence=1\&isAllowed=y. Accessed 30 Dec 2018.

2. Karunaweera ND, Ferreira MU. Leishmaniasis: current challenges and prospects for elimination with special focus on the south Asian region. Parasitology. 2018;145:425-9

3. Siriwardena HV, Udagedara CU, Karunaweera ND. Clinical features, risk factors and efficacy of cryotherapy in cutaneous leishmaniasis in Sri Lanka. Ceylon Med J. 2003;48(1):10-2.

4. Karunaweera ND, Pratlong F, Siriwardane HVYD, Ihalamulla RL, Dedet JP. Sri Lankan cutaneous leishmaniasis is caused by Leishmania donovani zymodeme MON-37. Trans Royal Soc Trop Med Hyg. 2003;97:380-1.

5. Siriwardana HVY, Noyes HA, Beeching NJ, Chance ML, Karunaweera ND, Bates PA. Leishmania donovani and cutaneous leishmaniasis, Sri Lanka. Emerg Infect Dis. 2007;13(3):476-8.

6. Rajapaksa US, Ihalamulla RL, Karunaweera ND. First report of mucosal tissue localisation of leishmaniasis in Sri Lanka. Ceylon Med J. 2005;50(2):90-1.

7. Semage SN, Pathirana KPN, Agampodi SB. Cutaneous leishmaniasis in Mullaitivu, Sri Lanka: a missing endemic district in the leishmaniasis surveillance system. Int J Infect Dis. 2014;25:53-5.

8. Siriwardana Y, Zhou G, Deepachandi B, Akarawita J, Wickremarathne C, Warnasooriya $W$, et al. Trends in recently emerged Leishmania donovani induced cutaneous leishmaniasis, Sri Lanka, first 13 years. Biomed Res Int. 2019a. https://doi.org/10.1155/4093603.

9. Rathnayake D, Ranawake RR, Sirimanna G, Siriwardhane Y, Karunaweera N, De Silva R. Co-infection of mucosal leishmaniasis and extra pulmonary tuberculosis in a patient with inherent immune deficiency. Int J Dermatol. 2010;49(5):549-51.

10. Siriwardana HVYD, Karunanayake P, Goonerathne L, Karunaweera ND. Emergence of visceral leishmaniasis in Sri Lanka: a newly established health threat. Pathog Glob Health. 2017;111(6):317-26.

11. Manokaran P, Sivansuthan S, Pratheepan GJ, Gajanthan R. Locally acquired visceral leishmaniasis- first reported case in Northern Province of Sri Lanka. Int J Med Microbiol Trop Dis. 2017:3(3):133-4.

12. Refai FW, Madarasingha NP, Fernandopulle R, Karunaweera N. Nonresponsiveness to standard treatment in cutaneous leishmaniasis: a case series from Sri Lanka. Trop Parasitol. 2016;6:155-8.

13. Siriwardana HVYD, Deepachandi B, Warnasuriya W, Gunesekara C, Karunaweera ND. Dermotropic Leishmania donovani: an insight in to rare and atypical clinical variants of CL. J Trop Med. 2019b; Manuscript accepted for publication.

14. Siriwardana HV, Thalagala N, Karunaweera ND. Clinical and epidemiologica studies on the cutaneous leishmaniasis caused by Leishmania donovani in Sri Lanka. Ann Trop Med Parasitol. 2010;104(3):213-23.

15. Kariyawasam KKGDUL, Edirisuriya CS, Senerath U, Hensmen D, Siriwardana HVYD, Karunaweera ND. Characterisation of cutaneous leishmaniasis in Matara district, southern Sri Lanka: evidence for case clustering. Pathog Glob Health. 2015;109(7):336-43.

16. Ranasinghe $S$, Wickremasinghe $R$, Munasinghe A, Hulangamuwa $S$, Sivanantharajah S, Seneviratne $\mathrm{K}$, et al. Cross-sectional study to assess risk factors for leishmaniasis in an endemic region in Sri Lanka. Am J Trop Med Hyg. 2013;89(4):742-9.

17. Siriwardana YD, Deepachandi B, Ranasinghe S, Soysa P, Karunaweera ND. Evidence for seroprevalence in human localized cutaneous leishmaniasis caused by Leishmania donovani in Sri Lanka. Biomed Res Int. 2018;6:1-7.

18. Kothalawala HS, Karunaweera ND. Loop-mediated isothermal amplification assay as a sensitive diagnostic tool for Leishmania donovani infections in Sri Lanka. Ceylon Med J. 2016;61:68-70.

19. Salam MA, Mondal D, Kabir M, Ekram ARMS, Haque R. PCR for diagnosis and assessment of cure in kala-azar patients in Bangladesh. Acta Trop. 2010;113:52-5.
20. Yehia L, Adib-Houreih M, Raslan WF, Kibbi A, Loya A, Firooz A, et al. Molecular diagnosis of cutaneous leishmaniasis and species identification: analysis of 122 biopsies with varied parasite index. J Cutan Pathol. 2012;39:347-55.

21. Toz SO, Culha G, Zeyrek FY, Ertabaklar H, Alkan MZ, Vardarli AT, et al. A realtime ITS1-PCR based method in the diagnosis and species identification of Leishmania parasite from human and dog clinical samples in Turkey. PLoS Negl Trop Dis. 2013;7(5):e2205.

22. Mohammadiha A, Dalimi A, Mahmoodi MR, Parian M, Pirestani M, Mohebali M. The PCR-RFLP-based detection and identification of the Leishmania species causing human cutaneous leishmaniasis in the Khorasan-Razavi Province, Northeast of Iran. J Arthropod Borne Dis. 2017:11(3):383-92.

23. Teimouri A, Mohebali M, Kazemirad E, Hajjaran H. Molecular identification of agents of human cutaneous leishmaniasis and canine visceral leishmaniasis in different areas of Iran using internal transcribed spacer 1 PCR-RFLP. J Arthropod Borne Dis. 2018;12(2):162-71.

24. Ranasinghe $\mathrm{S}$, Wickremasinghe R, Hulangamuwa S, Sirimanna G, Opathella N, Maingon RDC, Chandrasekharan V. Polymerase chain reaction detection of Leishmania DNA in skin biopsy samples in Sri Lanka where the causative agent of cutaneous leishmaniasis is Leishmania donovani. Mem Inst Oswaldo Cruz. 2015;110(8):1017-23.

25. da Silva MAL, Soares CRP, Medeiros RA, Medeiros Z, de Melo FL. Optimization of single-tube nested PCR for the diagnosis of visceral leishmaniasis. Exp Parasitol. 2013;134:206-10.

26. Gomes ALV, Silva AM, Cordeiro MT, Guimaraes GF, Marques ETA, Abath FGC Single-tube nested PCR using immobilized internal primers for the identification of denque virus serotypes. J Virol Methods. 2007;145(1):76-9.

27. Mendes CL, Abath FG, Leal NC. Development of a multiplex single-tube nested PCR (MSTNPCR) assay for Vibrio cholerae 01 detection. J Microbiol Methods. 2008;72:191-6.

28. Pontes NE, Barbosa CN, Jesus ALS, Silva JG, Freitas AC. Development and evaluation of single-tube nested PCR (STNPCR) for the detection of porcine circovirus type 2 (PCV2). Transbound Emerg Dis. 2014;61:233-8.

29. Lima JF, Guedes GM, Lima JF, Lira LA, Santos FC, Arruda ME, et al. Singletube nested PCR assay with in-house DNA extraction for Mycobacterium tuberculosis detection in blood and urine. Rev Soc Bras Med Trop. 2015; 48(6):731-8.

30. Cruz I, Canavate C, Rubio JM, Morales MA, Chicharro C, Laquna F, et al. A nested polymerase chain reaction (In-PCR) for diagnosing and monitoring Leishmania infantum infection in patients co-infected with human immuno-deficiency virus. Trans R Soc Trop Med Hyg. 2002;96 supplement 1:S1/185-S1/189.

31. Nucleotide database, National center for biotechnology information (NCBI). https://www.ncbi.nlm.nih.gov/. Accessed 31 Dec 2018.

32. Jones S, Carley S, Harrison M. An introduction to power and sample size estimation. Emerg Med J. 2003:20:453-8.

33. Ihalamulla RL, Siriwardana YD, Karunaweera ND. Efficacy of RPMI 1640 and M 199 media in the isolation of Leishmania from cutaneous lesions. Ann Trop Med Parasitol. 2008;102(2):173-5.

34. Lachaud L, Chabbert E, Dubessay P, Reynes J, Lamothe J, Bastien P. Comparison of various sample preparation methods for PCR diagnosis of visceral leishmaniasis using peripheral blood. J Clin Microbiol. 2001;39:613-7.

35. Basic Cost Accounting for Clinical Services; Approved Guideline. Clinical and laboratory standards institute. 1998. http://www.zxyjhjy.com/upload/ attached/file/20170406/20170406161022_3347.pdf. Accessed 31 Dec 2018.

36. van Eys GJ, Schoone GJ, Kroon NC, Ebeling SB. Sequence analysis of small subunit ribosomal RNA genes and its use for detection and identification of Leishmania parasites. Mol Biochem Parasitol. 1992;51:133-42.

37. Ferreira LR, Kesper $N$, Teixeira MM, Laurenti MD, Barbieri CL, Lindoso JA, Umezawa ES. New insights about cross-reactive epitopes of six trypanosomatid genera revealed that Crithidia and Leptomonas have antigenic similarity to L. (L.) chagasi. Acta Trop. 2014;131:41-6.

38. Ahuja K, Arora G, Khare P, Selvapandiyan A. Selective elimination of Leptomonas from the in vitro co-culture with Leishmania. Parasitol Int. 2015 64(4):1-5

39. Pecharatana S, Pickett MA, Watt PJ, Ward ME. Genotypin ocular strains of Chlamydia trachomats by single-tube nested PCR. Genome Res. 1993:3:200-4.

40. Ylitalo N, Bergstrom T, Gyllensten U. Detection of genital human papillomavirus by single-tube nested PCR and type-specific oligonucleotide hybridization. J Clin Microbiol. 1995;33(7):1822-8.

41. Tilston P, Corbitt G. A single tube nested PCR for the detection of hepatitis C virus RNA. J Virol Methods. 1995;53:121-9. 
42. Abath FG, Melo FL, Werkhauser RP, Montenegro L, Montenegro R, Schindler HC. Single-tube nested PCR using immobilized internal primers. Biotechniques. 2002;33:1210-4.

43. Feray C, Samuel D, Thiers V, Gigou M, Pichon F, Bismuth A, et al. Reinfection of liver graft by hepatitis $\mathrm{C}$ virus after liver transplantation. J Clin Invest. 1992:89:1361-5.

44. Yourno J. A method for nested PCR with single closed reaction tubes. PCR Methods Appl. 1992;2:60-5.

45. Wolff C, Hornschemeyer D, Wolff D, Kleesiek K. Single-tube nested PCR with room temperature stable reagents. PCR Methods Appl. 1995;4:376-9.

46. Melo FL, Gomes AL, Barbosa CS, Werkhauser RP, Abath FG. Development of molecular approaches for the identification of transmission sites of schistosomiasis. Trans R Soc Trop Med Hyg. 2006;100:1049-55.

47. Montenegro LML, Montenegro RA, Lima AS, Carvalho AB, Schindler HC, Abath FGC. Development of a single tube hemi-nested PCR for genus specific detection of Plasmodium in oligoparasitemic patients. Trans R Soc Trop Med Hyg. 2004;98:619-25.

48. Souza G, Abath F, Leal N, Farias A, Almeida A. Development and evaluation of a single tube nested PCR based approach (STNPCR) for the diagnosis of plague. Adv Exp Med Biol. 2007;603:351-9.

\section{Publisher's Note}

Springer Nature remains neutral with regard to jurisdictional claims in published maps and institutional affiliations.

Ready to submit your research? Choose BMC and benefit from:

- fast, convenient online submission

- thorough peer review by experienced researchers in your field

- rapid publication on acceptance

- support for research data, including large and complex data types

- gold Open Access which fosters wider collaboration and increased citations

- maximum visibility for your research: over $100 \mathrm{M}$ website views per year

At BMC, research is always in progress.

Learn more biomedcentral.com/submissions 